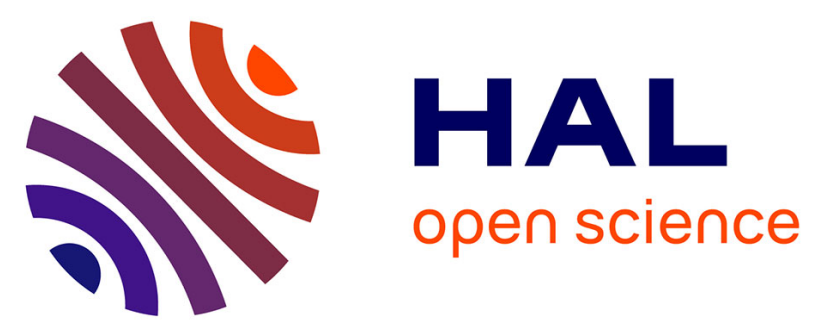

\title{
Microstructures of Metallic NiCrBSi Coatings Manufactured via Hybrid Plasma Spray and In Situ Laser Remelting Process
}

Nicolas Serres, Françoise Hlawka, Sophie Costil, Cécile Langlade, Frédérique Machi

\section{To cite this version:}

Nicolas Serres, Françoise Hlawka, Sophie Costil, Cécile Langlade, Frédérique Machi. Microstructures of Metallic NiCrBSi Coatings Manufactured via Hybrid Plasma Spray and In Situ Laser Remelting Process. Journal of Thermal Spray Technology, 2011, 20 (1-2), pp.336-343. hal-00677230

\section{HAL Id: hal-00677230 \\ https://hal.science/hal-00677230}

Submitted on 7 Mar 2012

HAL is a multi-disciplinary open access archive for the deposit and dissemination of scientific research documents, whether they are published or not. The documents may come from teaching and research institutions in France or abroad, or from public or private research centers.
L'archive ouverte pluridisciplinaire HAL, est destinée au dépôt et à la diffusion de documents scientifiques de niveau recherche, publiés ou non, émanant des établissements d'enseignement et de recherche français ou étrangers, des laboratoires publics ou privés. 


\title{
Microstructures of Metallic NiCrBSi Coatings Manufactured via Hybrid Plasma Spray and In Situ Laser Remelting Process
}

\author{
Nicolas Serres, Françoise Hlawka, Sophie Costil, Cécile Langlade, and Frédérique Machi
}

(Submitted April 13, 2010; in revised form September 12, 2010)

\begin{abstract}
This paper deals with coating alternatives to hard chromium plating. Thermal spraying is already used in industry, but results are not always satisfactory for reasons of porosity and microstructures. In this study, atmospheric plasma spraying (APS) and in situ laser irradiation by diode laser processes were combined to modify the structural characteristics of thick NiCrBSi alloy layers. The microstructure evolution was studied, and results show that in situ laser remelting induced the growth of a dendritic structure, which strongly decreased the porosity of as-sprayed coatings and increased the adhesion on the substrate. Moreover, no phase transition after laser treatment was observed. Lastly, a mechanical investigation demonstrated that the combination between plasma spray and in situ melting with a diode laser could result in very good mechanical properties. The increase of the laser incident power involved an increase of the mean contact pressure, along with coating hardness. The hybrid process appears to be a possible alternative to hard chromium plating, in order to protect mechanical parts, because of the improved mechanical properties of the NiCrBSi layer.
\end{abstract}

Keywords adhesion, nanoindentation, NiCrBSi, plasma-laser hybrid process, scratch testing

\section{Introduction}

Electrodeposited hard chromium plating is generally used to produce hard and wear-resistant coatings (Ref 1). However, the plating baths contain hexavalent chromium, which has adverse health and environmental effects (Ref 2 ) and is forbidden by European regulations $(\operatorname{Ref} 3)$. That is the reason why some coating alternatives are currently studied, mainly with thermal spraying. However, results are not always as good as a hard chromium deposit as shown by the altered microstructure in the as-sprayed sample. Coating discontinuities are induced by the

This article is an invited paper selected from presentations at the 2010 International Thermal Spray Conference and has been expanded from the original presentation. It is simultaneously published in Thermal Spray: Global Solutions for Future Applications, Proceedings of the 2010 International Thermal Spray Conference, Singapore, May 3-5, 2010, Basil R. Marple, Arvind Agarwal, Margaret M. Hyland, Yuk-Chiu Lau, Chang-Jiu Li, Rogerio S. Lima, and Ghislain Montavon, Ed., ASM International, Materials Park, OH, 2011.

Nicolas Serres and Françoise Hlawka, LGéCo-LISS, INSA de Strasbourg, 24 Boulevard de la Victoire, 67084 Strasbourg Cedex, France; Sophie Costil and Cécile Langlade, LERMPS, Université de Technologie de Belfort-Montbéliard, site de Sévenans, 90010 Belfort Cedex, France; and Frédérique Machi, IREPA LASER, Parc d'Innovation, 67400 Illkirch-Graffenstaden, France. Contact e-mail: nicolas.serres@insa-strasbourg.fr. porosity, the presence of unmelted particles, and the interlamellar boundaries within the coating; that is, it is not possible to achieve defect-free thermal spray coatings, which induce weak wear and corrosion resistance. Lasers present the advantage of building denser coatings, with finer microstructures (Ref 4). Moreover, a laser post-treatment can be conducted on as-sprayed samples to increase their mechanical properties (Ref 5).

A laser post-treatment can generate some cracks in an as-sprayed coating, one of the major defects that can occur during the solidification of the metallic alloy, because of a high thermal gradient due to the high temperature of the small irradiated area (Ref 6). In this study, atmospheric plasma spraying (APS) and laser irradiation by diode laser processes were combined in situ to modify structural characteristics of NiCrBSi coatings. The technique is not new as it was applied in the past as a combination of plasma spraying and a continuous wave $(\mathrm{CW}) \mathrm{CO}_{2}$ laser irradiation (Ref 7). However, generally this procedure was applied to ceramic layers to build coatings that exhibited distinctly reduced porosity, uniform microstructure, high hardness, and highly adhesive bonding to the substrate (Ref 8).

Nickel-based coatings are usually used in applications where corrosion and wear resistance are required at moderate and elevated temperatures, and, among them, $\mathrm{NiCrBSi}$ presents particularly good performances (Ref 9). This material is a self-fluxing alloy; the presence of boron increases the self-fluxing properties of the alloy by the formation of eutectic phases at $3.6 \%$ of $\mathrm{B}$ in weight (Ref 10). There are also a lot of established treatments applied to melt NiCrBSi alloys, such as flame, thermal treatment, laser post treatment, and so forth. This material is generally remelted for industrial applications, which can 
lead to strongly increased corrosion and wear resistance, as the alloy is melted and cast into some products. In an earlier work, the good wear resistance properties of $\mathrm{NiCrBSi}$ coated by laser cladding with a diode laser were demonstrated (Ref 11), making this material an alternative to electrolytic hard chromium plating. The in situ treatment can be also a substitute to this electrochemical treatment, especially if its mechanical behavior is as good as that of hard chromium plating.

In this paper, several technical parameters are investigated, especially the laser power density, to establish the best configuration to obtain coatings without solidification cracking (Ref 12). One of the advantages of this in situ process is that the high spray velocity reduces the treatment time compared with a post-treatment method. It also decreases the thermal gradient, because of the preheating of the substrate by the plasma gun.

\section{Experimental Procedure}

\subsection{Feedstock Materials}

NiCrBSi powders from Höganäs, referenced as grade $1160-00$ and 1140-00 were chosen as feedstock materials. The composition of the sprayed powders is listed in Table 1 . However, the results discussed in this paper are mostly for alloy $1160-00$, which contains more chromium and has surely better mechanical properties, such as hardness (Ref 13). Thus, this alloy seems better able to replace hard chromium plating to resist wear than alloy 1140-00. The substrate material was C38 steel in the form of a disc, $10 \mathrm{~mm}$ thick, with a diameter of $25 \mathrm{~mm}$.

\subsection{Processing Parameters}

The experimental device of the hybrid plasma spray process consisted of an F4 plasma spray gun from SulzerMetco and a diode laser ( $3 \mathrm{~kW}$, average power) of $848 \mathrm{~nm}$ wavelength, from Laserline (Fig. 1). Before the spraying operations, samples were degreased with acetone and alcohol and grit blasted with $\mathrm{Al}_{2} \mathrm{O}_{3}$ (particle size: $250 \mu \mathrm{m}$ ) to obtain a surface with a mean roughness of about $5 \mu \mathrm{m}$. This operation allows mechanical bonding between the coating and the substrate. Then samples were placed on a holder that moved linearly, and they were swept by the plasma gun and remelted in situ by the laser. The coating feedstock material was injected vertically into the plasma jet by Ar carrier gas. In situ laser remelting is able to reduce cooling stresses by requiring a low level of laser energy. To reduce the sample surface temperature,

Table 1 Chemical composition of the spray powders

\begin{tabular}{lccccccc}
\hline & \multicolumn{7}{c}{ Chemical composition, wt.\% } \\
\cline { 2 - 8 } Powder & $\mathbf{C}$ & Ni & Fe & \multicolumn{1}{c}{ Cr } & Si & B & O \\
\hline $1140-00$ & 0.26 & 84.7 & 2.51 & 7.46 & 3.40 & 1.63 & 0.042 \\
$1160-00$ & 0.76 & 72.33 & 3.87 & 15.16 & 4.65 & 3.19 & 0.043 \\
\hline
\end{tabular}

cooling systems controlled by air jets were placed at the rear of the holder. This positioning allows the reduction of the thermal gradient, which avoids the formation of cracks. It is believed that the laser power density (LPD) has a significant effect on the properties of the sample. Thus, two fixed-focus lenses of $0.8 \times 2 \mathrm{~mm}^{2}$ and $2 \times 4 \mathrm{~mm}^{2}$ were used to cover a large range of LPD. These two specific systems allowed irradiated areas of $8 \mathrm{~mm}^{2}$ (OS1) and $1.6 \mathrm{~mm}^{2}$ (OS2). Some variations were evaluated, regarding the evolution of the properties of different samples depending on the laser power density, which is abbreviated as " $D$." The selected processing parameters are specified in Table 2. Hard chromium samples were provided by a French electroplating industry, using common parameters $\left(45 \mathrm{~A} / \mathrm{dm}^{2}, 53{ }^{\circ} \mathrm{C}, 350 \mathrm{~g} / \mathrm{L}\right.$ chromic acid).

Furthermore, to measure the surface temperature, a thermal camera (Flir systems-ThermaCAM SC3000) that could work at a frequency of $900 \mathrm{~Hz}$ was used. Every $1.1 \mathrm{~ms}$, a thermal image of the sample was taken that allowed observation and measurement of the surface temperature during laser melting treatment. Some measurements were compared with values obtained with a contact thermocouple in order to calibrate the emissivity value of the treated samples.

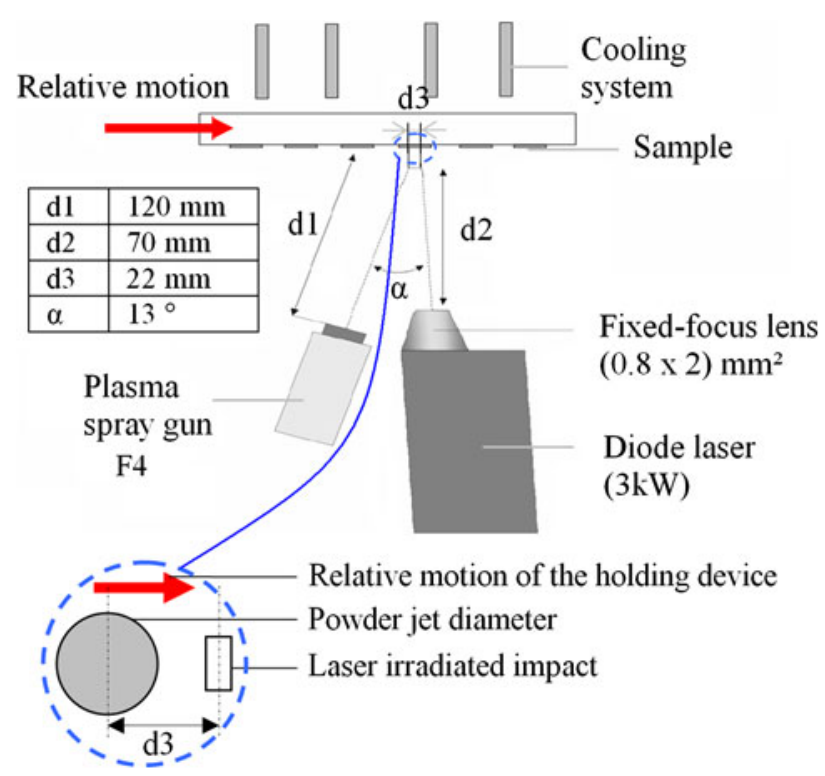

Fig. 1 Experimental setup consisting of an F4 plasma spray gun and a diode laser

Table 2 Processing parameters of the spray powders

\begin{tabular}{cclc}
\hline & $\begin{array}{c}\text { Melting } \\
\text { temperature, } \\
{ }^{\circ} \mathbf{C}\end{array}$ & Morphology & Particle size distribution \\
\hline $1140-00$ & $1030-1060$ & Spherical & $20-63 \mu \mathrm{m}($ average $45 \mu \mathrm{m})$ \\
$1160-00$ & $980-1020$ & Spherical & $20-63 \mu \mathrm{m}($ average $45 \mu \mathrm{m})$ \\
\hline
\end{tabular}




\subsection{Coating Characterization}

2.3.1 Microstructure Observation. The samples were cut using a diamond saw and were mounted using a resin. Mounted cross sections were polished following standard metallographic techniques using diamond slurry to achieve a final roughness of about $R_{\mathrm{a}} \approx 0.02 \mu \mathrm{m}$. Then, the microstructure evolution was studied, with the analysis of the chemical composition, implementing energydispersive spectroscopy and $\mathrm{x}$-ray diffraction $(40 \mathrm{kV}$, $30 \mathrm{~mA}, \mathrm{Cu} \mathrm{K} \alpha$ radiation at $0.154 \mathrm{~nm}$ ). A $2 \theta$ scanning step of $0.03^{\circ}$ and a measuring time between each step of $5 \mathrm{~s}$ were used to determine the peak positions of the different $\mathrm{NiCrBSi}$ phases in the range of $30^{\circ}<2 \theta<80^{\circ}$. X-ray diffraction (XRD) measurements were carried out on polished surfaces of bulk samples in order to work in the same conditions for all coatings.

2.3.2 Adhesion and Cohesion Measurements. It is not easy to evaluate with accuracy the adhesion value of lasertreated samples, and for adhesion testing, tensile standard tests such as ASTM C633 and EN 582 are not always sufficient. Thus, a scratch test on cross sections of coatings was applied in this paper. This method is described by Lopez et al. (Ref 14) and Nohava et al. (Ref 15).

Adhesion measurements of the samples were carried out by a scratch test method with a constant load on a polished cross section of the coating. The indenter moved from the substrate through the coating into the resin where the sample was embedded. A Rockwell C diamond indenter of $200 \mu \mathrm{m}$ radius was used for all tests. The test was repeated at several loads in the range of $5<F(\mathrm{~N})<120$ and the projected area of the cone, extracted by the indenter, was calculated (Fig. 2). The projected cone area, $A$ (Eq 1 and see also Fig. 2) was chosen as the most characteristic factor among $a$ and $b$ values since only $A$ showed a monotonic relationship to the scratching load.

$A=\frac{1}{2} a \times b$

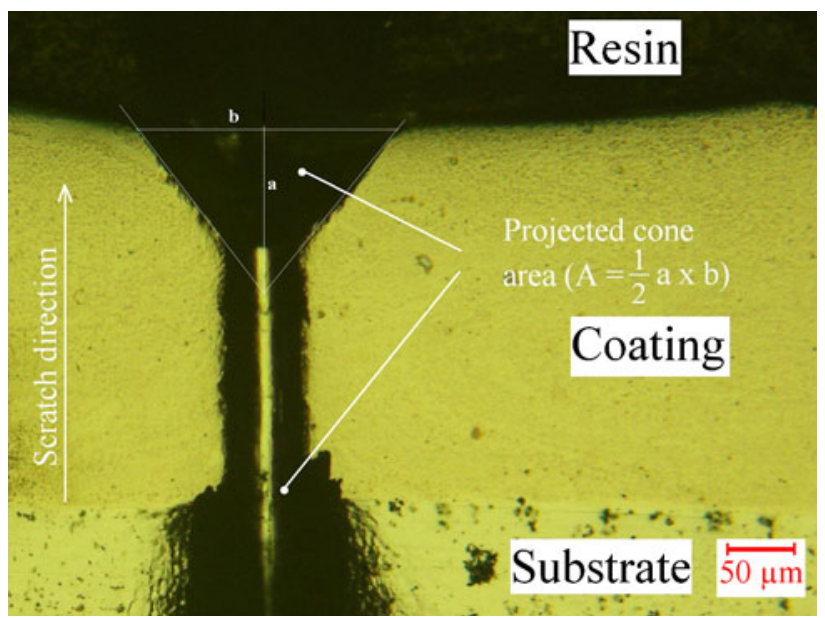

Fig. 2 Scratch test, on a cross-sectioned NiCrBSi remelted sample (grade 1160-00), carried out to calculate adhesion and cohesion of the samples
Two types of failure can be observed: the cone originates from the coating, and the cone originates from the substrate/coating interface. In the first case the cohesion of the coating can be characterized, while in the latter case the adhesion of the coating can be characterized (Ref 14).

2.3.3 Nanoindentation Tests. Hardness and effective Young's elastic modulus of the remelted samples were determined using an ultralow load indentation system equipped with a Berkovich indenter tip. This microprobe records continuously both the load and the displacement as indents are made on a sample, with resolutions up to $75 \mathrm{nN}$ and $0.04 \mathrm{~nm}$, respectively. Depending on Ref 16, the mean contact pressure is only related to hardness. Thirty indentations were made on selected samples at different loads in the range of $7.5-30 \mathrm{mN}$ on coated polished cross sections. The effective Young's modulus and the hardness were then calculated from the Oliver-Pharr model (Ref 17), and the results were averaged. The Poisson's ratio of the different treated samples was assumed equal to 0.32 .

\section{Results and Analysis}

\subsection{Influence of the Laser-Irradiated Area}

The size of the laser-irradiated area depends on the selected optic. In this paper, two specific systems were investigated with an irradiated area of $8 \mathrm{~mm}^{2}$ (OS1) and $1.6 \mathrm{~mm}^{2}$ (OS2). These optical systems were implemented to evaluate the influence of the irradiation time and the input energy on the resulting molten state. It seems obvious that the optical system OS1 is not good enough to melt the layer (Fig. 3a). Firstly, a large unmelted area is observed; secondly, a delamination in the coating is also observed. These results are due to the energy density that strongly decreases with the use of OS1. Thus, it is not possible to melt the layer. Finally, the optical system OS2 was chosen, because it allows an elevated irradiance to be kept with one of the spot dimensions as high as possible in order to irradiate near the spraying spot of $6 \mathrm{~mm}$ diameter.

In addition, with OS2, the laser power density can reach $1875 \mathrm{~W} / \mathrm{mm}^{2}$ with the melting of the $40 \mu \mathrm{m}$ sprayed layer. Under $1400 \mathrm{~W} / \mathrm{mm}^{2}$, it is not possible to homogeneously melt this layer with an a posteriori system laser melting procedure (Fig. 4). Although 1140-00 and 1160-00 alloys have a melting point difference of about $50{ }^{\circ} \mathrm{C}$, the changes in melting thickness show an identical behavior. Also, the melting ability does not exhibit any variation when the laser power density increases from 1600 to $1800 \mathrm{~W} / \mathrm{mm}^{2}$. However, the real gap in this figure is observed for values higher than $1250 \mathrm{~W} / \mathrm{mm}^{2}$, because more than $30 \mu \mathrm{m}$ are melted, which corresponds to the thickness of the as-sprayed layer coated by the plasma gun alone on one step. The coatings were produced step by step to achieve a final thickness of about $250 \mu \mathrm{m}$ (i.e., four steps). Thus, if the remelted thickness is equal to more than the as-sprayed thickness coated by the plasma gun, the influence of the laser does not provide a delamination in the in situ configuration, because thermal stresses are limited by 

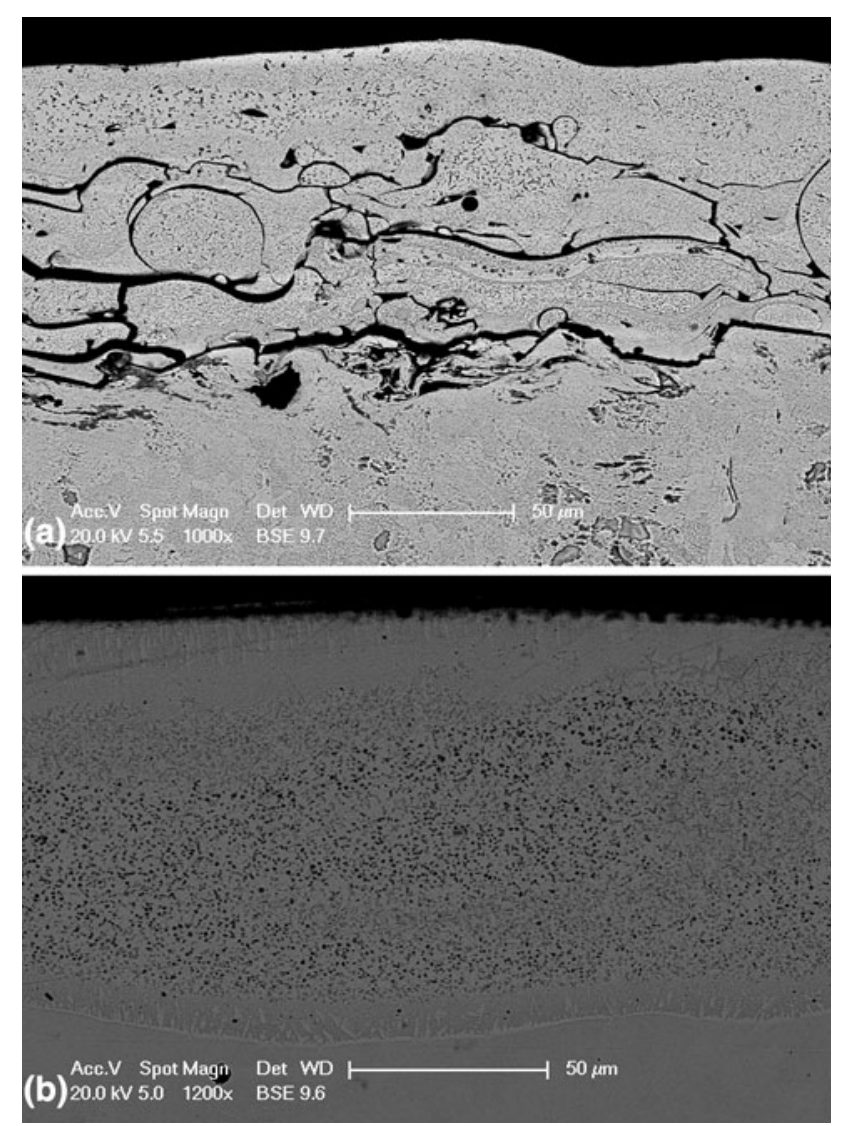

Fig. 3 SEM cross-section images of the plasma sprayed lasermelted coatings (grade 1160-00) with OS1 (a) and OS2 (b). Both images represent samples that are carried out with two steps of treatment, which explain the reduced thickness

the reduced thermal gradient (the in situ configuration allows an increase in the sample temperature). The thickness of coating is very important in this case. Indeed, a high temperature gradient, between as-sprayed and laser-treated areas, will lead to the creation of thermal stresses, which will favor the generation of cracks. The difficulty that can arise is a delamination of the deposit in the as-sprayed/melted interface. Without preheating the surface, it is possible to melt only about $30 \mu \mathrm{m}$ at $1250 \mathrm{~W} / \mathrm{mm}^{2}$. However, with an in situ configuration, the viscosity of the alloy coupled with the homogenization of the layer allows an increase in the melting thickness $(\operatorname{Ref} 18,19)$, to a value of $40 \mu \mathrm{m}$. Indeed, the cross section is homogeneous without as-sprayed (i.e., unmelted) areas (Fig. 3b).

\subsection{Adhesion and Cohesion Measurements}

Whatever the irradiance, the microstructure resulting from laser treatment exhibits a dendritic structure (Fig. 5). The remelting of the coating reduces porosity and creates a strong metallurgical bond (see also section 3.3) between the coating and the substrate, which also enhances the cohesion between the particles of the coating, without the propagation of cracks (Fig. $6 \mathrm{~b}$ ). As a consequence, the adhesion seems strongly increased compared with the

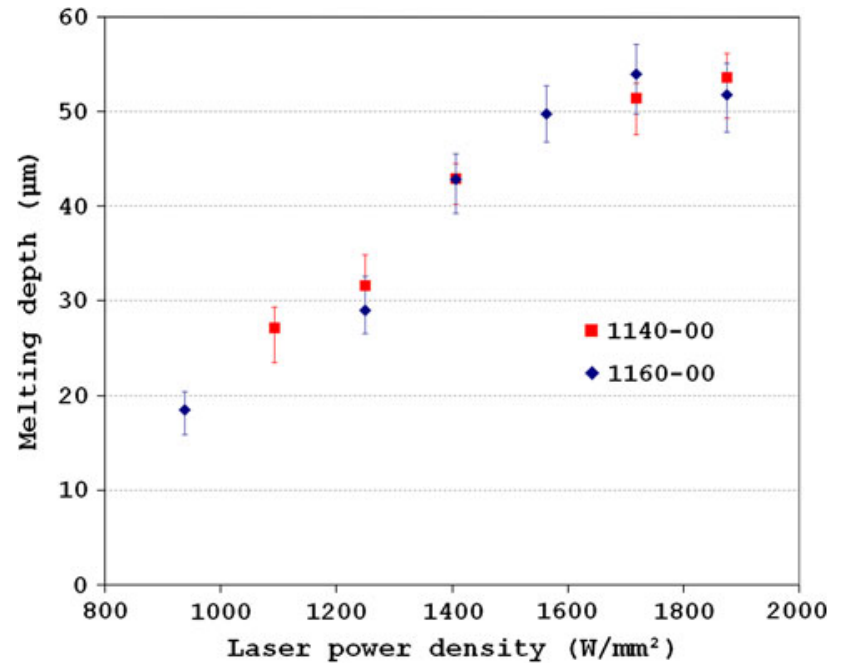

Fig. 4 Influence of the laser power density on the melting thickness for both feedstock materials. These results were produced with an a posteriori system laser melting system

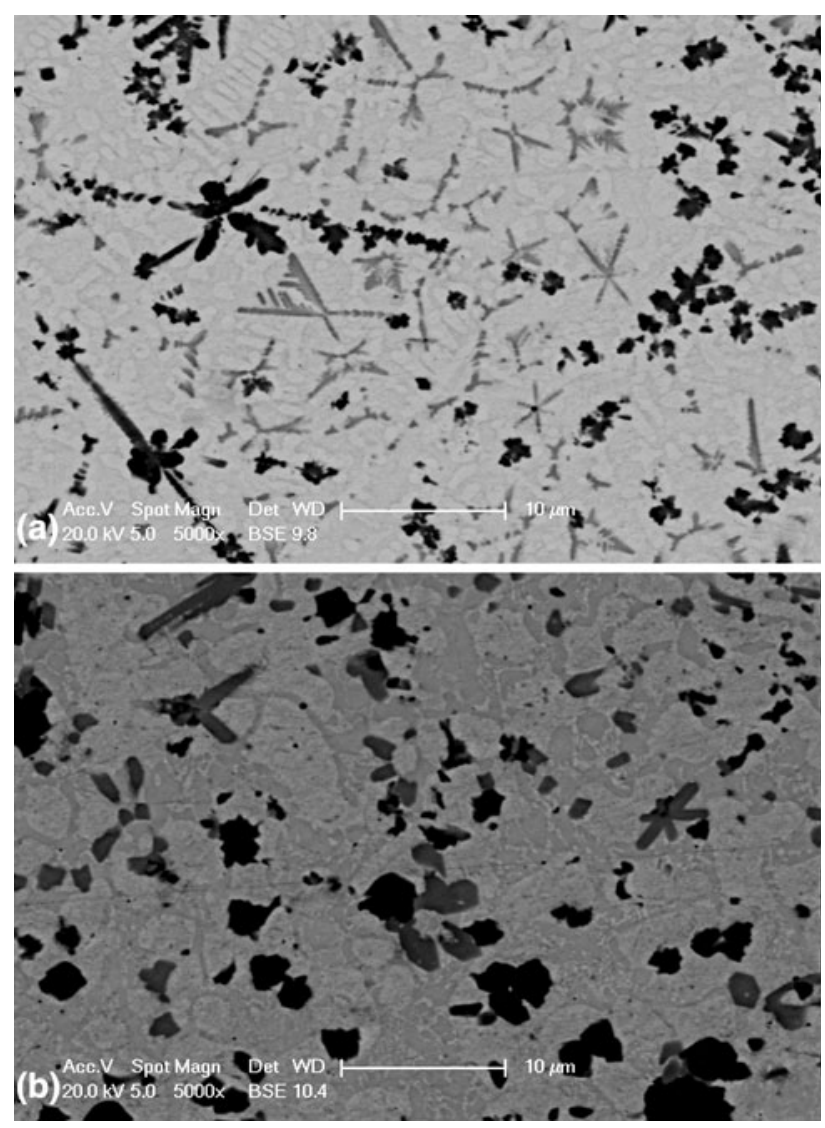

Fig. 5 Representative cross section morphologies of (a) in situ remelted at $D=1250 \mathrm{~W} / \mathrm{mm}^{2}$ and (b) at $D=1875 \mathrm{~W} / \mathrm{mm}^{2}$ NiCrBSi coatings (grade 1160-00). $D$, laser power density

APS process. Furthermore, all remelted samples present a finer microstructure and higher density than APS coatings. Even if no grain size measurements have been carried out 

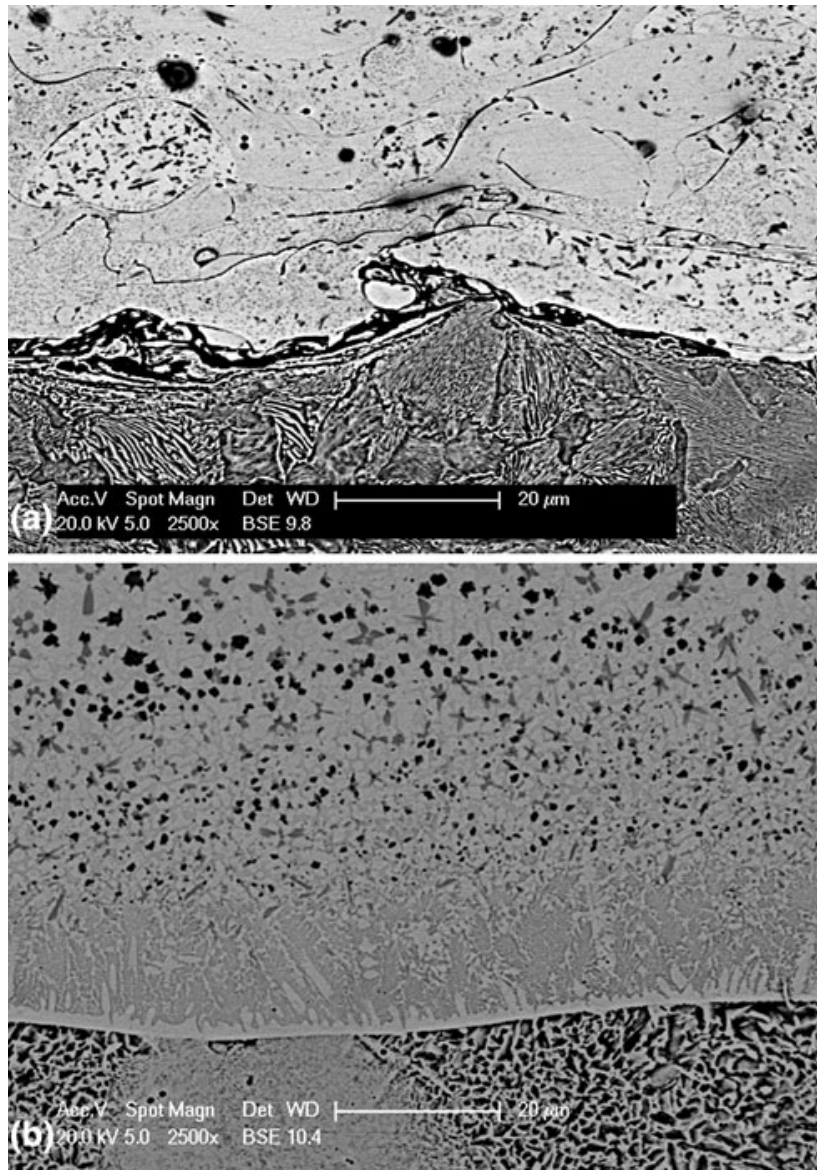

Fig. 6 Typical interface morphologies of (a) the as-sprayed and (b) the in situ remelted coatings (grade 1160-00)

to report this formation of finer structure after remelting, a slight peak broadening is observed in the studied diffraction patterns just as for the as-sprayed sample (see also section 3.4), which can be explained by a variation of the grain size.

The projected cone area increased with increasing scratching load (Fig. 7). This increase was almost linear for all samples. For all loads, the as-sprayed sample exhibited higher projected cone areas compared with the remelted NiCrBSi sample and hard chromium plating sample. Thus, this sample had a low cohesion as well as a low adhesion to the substrate. There is an influence of the porosity, which decreases the cohesion of the coating. At higher loads, the damage in the APS coating was larger than in the other tested coatings. For remelted samples and hard chromium plating, the projected cone area was very similar at loads down to $50 \mathrm{~N}$, but the failure mechanism was different at high loads and the remelted samples presented the best results, because the projected cone areas were the smallest. Electrodeposited hard chromium plating generally exhibits a quite compact and porosityfree microstructure, but these coatings have a structure based on a crack network. Thus, this specific microstructure facilitates the initiation and the propagation of crack
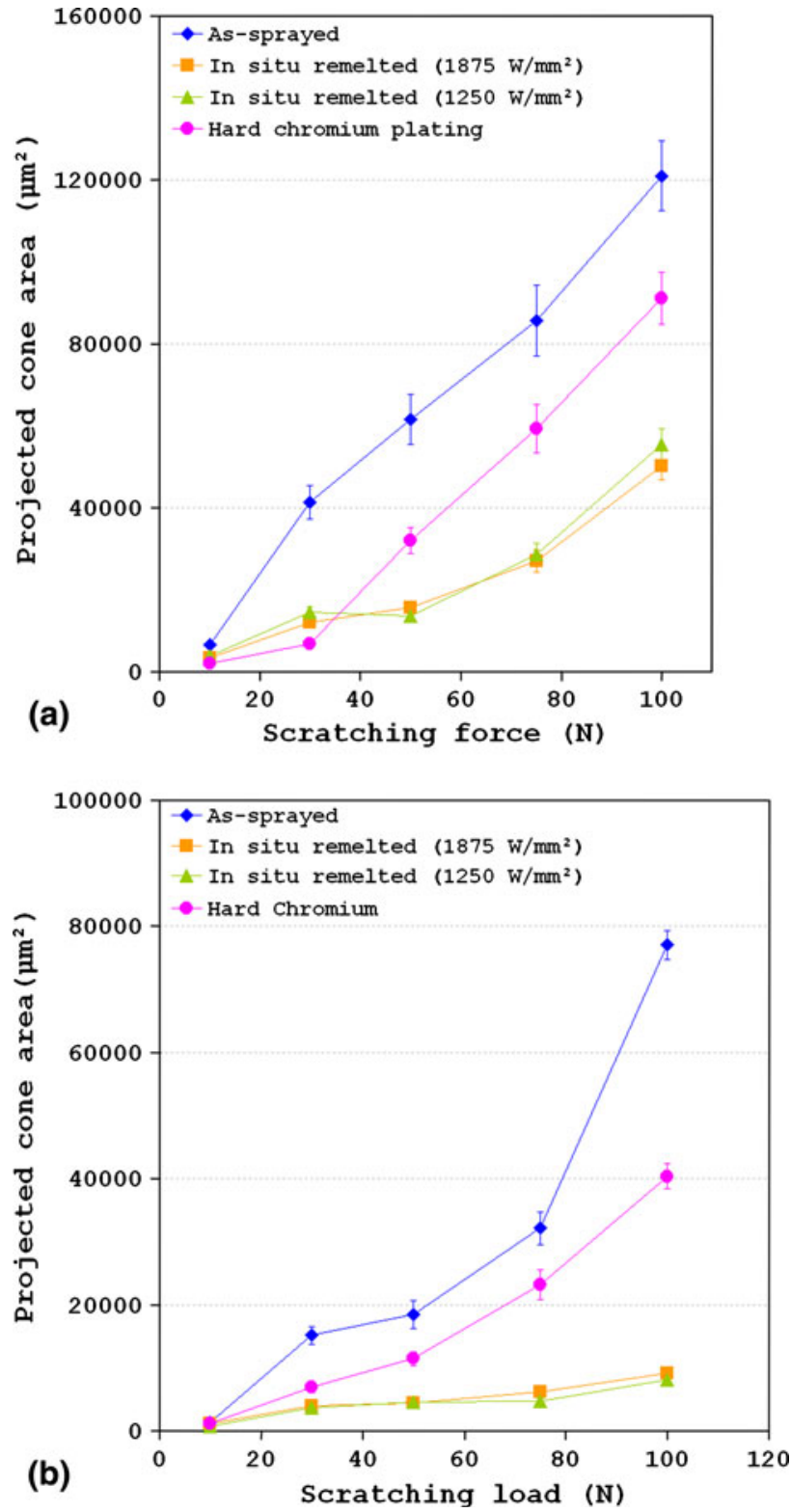

Fig. 7 Evolution of the projected cone area as a function of the scratch load for different samples. Results are related to the cohesion (a) and the adhesion (b) values of tested samples (grade 1160-00)

delamination in the layer, since crack growth occurs after increasing the load on the cross section. In addition, there is little difference with respect to the laser power density for adhesion results (Fig. 7b), and this is not a relevant factor in order to increase the adhesion of a remelted coating. Projected cone areas are closely related for both laser power densities, in the case of cohesion, as well as adhesion assessments (Fig. 7a, b).

\subsection{Influence of the Feedstock Powder}

The two feedstock powders studied in this paper are Ni-based self-fluxing alloys. The main difference between 
the two grades is the melting temperature, related to the boron wt.\% content. The evolution of the surface temperature was analyzed with a thermal camera. It was found that a temperature of about $1100{ }^{\circ} \mathrm{C}$ is quickly reached for both powders in the laser-treated area for $D=1875 \mathrm{~W} / \mathrm{mm}^{2}\left(T=990{ }^{\circ} \mathrm{C}\right.$ for $\left.D=1250 \mathrm{~W} / \mathrm{mm}^{2}\right)$. Furthermore, these temperatures increase with time. Even if the two feedstock powders have different melting temperatures, both of them present a metallurgical bond to the substrate. Also, their thermal conductivities are comparable.

There is a small amount of $\mathrm{Ni}, \mathrm{Cr}$, and $\mathrm{Si}$ at the interface (Fig. 8a, b), suggesting that the alloys melted and
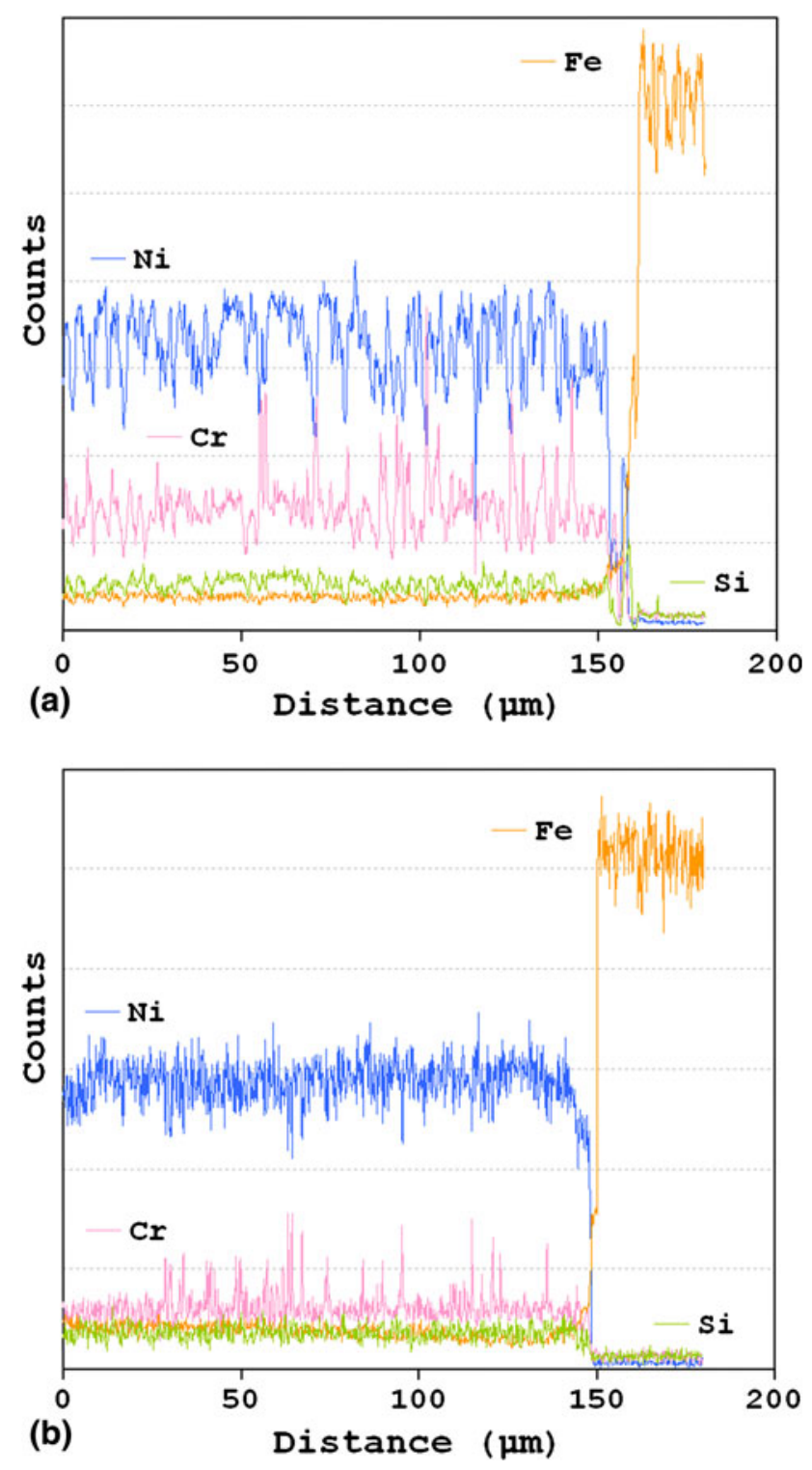

Fig. 8 Composition profiles of NiCrBSi 1160-00 (a) and 1140-00 (b) samples carried out by EDS on the cross section (These profiles were not recorded on the complete thickness of the samples, as the chemical composition was uniform across the whole thickness of the coatings) diffused into the substrate and subsequently formed a good metallurgical bond at the contact surface. The bond strength depends on the amount of melting that happened and varies with the holding time during treatment.

The chemical composition is homogeneous on the coating thickness for both feedstock powders, without diffusion of iron (main element of the substrate), though a high temperature is reached (Fig. 8a, b).

\subsection{Influence of the Selected Processing Parameters}

For the processing parameters selected for this study, the microstructures of the remelted sample are comparable, such as presented in Fig. 5. However, a small difference in the amount of black phase and its size is observed depending on the laser power density. The black phase has been identified as CrB type chromium borides, and they help increase the mechanical properties of the layer (Ref 20).

On the other hand, no difference was found during the chemical investigation by EDS except the presence of oxygen in the case of the as-sprayed sample due to a relatively high porosity rate, whereas some differences are observed regarding XRD analysis. This analysis reveals a considerable amount of possible phases resulting from the complexity of the NiCrBSi alloy coating (Fig. 9). In fact, the proximity between $\mathrm{Ni}, \mathrm{Cr}$, and $\mathrm{Fe}$ in the periodic table of chemical elements makes it difficult to find the real structure of this coating. Finally, some compositions consistent with the data are suggested. XRD patterns of the as-sprayed and in situ remelted samples reveal that the microstructure of the coating consists mainly of $\gamma-\mathrm{Ni}$, $(\mathrm{Cr}, \mathrm{Fe})_{7} \mathrm{C}_{3}, \mathrm{CrB}$, and $\mathrm{Ni}_{3} \mathrm{~B}$. The same phases are observed with APS and laser-treated samples, but there are some differences with the XRD spectra, regarding the peak

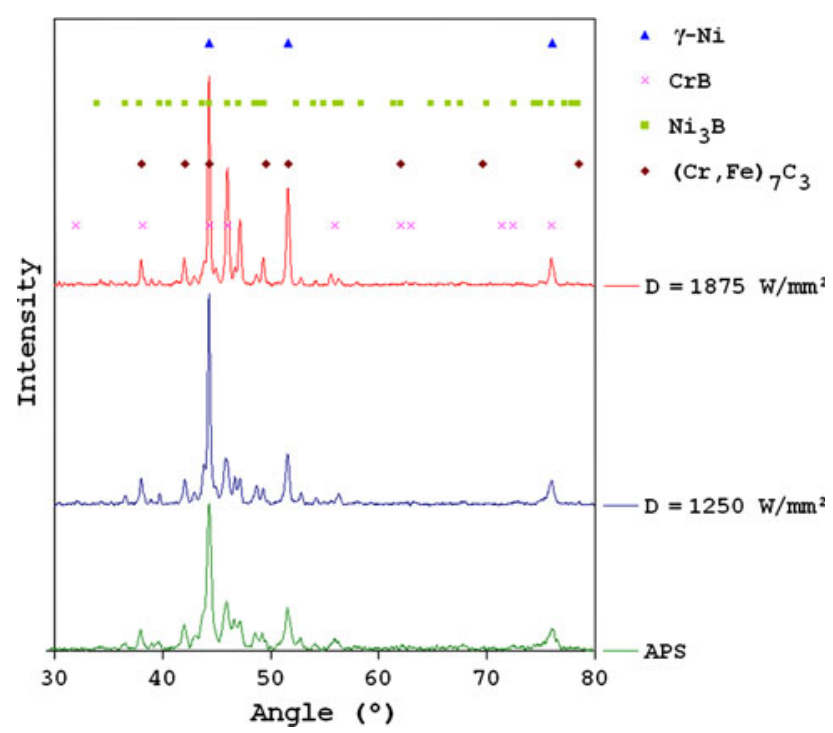

Fig. 9 XRD spectra of as-sprayed and remelted ( $D=1250$ and $1875 \mathrm{~W} / \mathrm{mm}^{2}$ ) coatings with the $1160-00$ feedstock powder 
intensities, that are smaller in the case of APS, resulting partly from the sample porosity. This dissimilarity can be explained either by the variation of microstresses repartitioned into the samples (the residual stress level decreases for in situ remelted coatings), by a variation of the grain size or by a combination of both phenomena. The differences between remelted samples regarding their XRD spectra are also the result of a variation of crystallization behavior of these samples, due to a specific solidification kinetic, depending on the selected processing parameters. The temperature was determined using a thermal camera and for $D=1875 \mathrm{~W} / \mathrm{mm}^{2}, T \approx 1350{ }^{\circ} \mathrm{C}$, whereas for $D=1250 \mathrm{~W} / \mathrm{mm}^{2}, T \approx 1100{ }^{\circ} \mathrm{C}$ at the end of the treatment. Thus, the thermal gradients are very different for both samples. An analog assessment could be assumed to explain the reduced peak intensity of as-sprayed samples, because the process temperature is once again different compared with the in situ remelted treatment of NiCrBSi layers. The laser beam, focused on a small area, improves the temperature on the sample surface, which allows modification in the crystallization process. In fact, XRD peaks are more sensitive to the crystalline size, and the NiCrBSi sample prepared by APS could present a reduction of crystallinity compared with the in situ remelted coating.

\subsection{Berkovich Nanoindentation}

Mean values of hardness and Young's modulus for laser-treated $\mathrm{NiCrBSi}$ measured by the nanoindentation test, with a $30 \mathrm{mN}$ load, are shown in Fig. 10. It was already shown that remelted samples have better mechanical properties than as-sprayed samples (Ref 20). The specific comparison between remelted samples demonstrates that the hardness values, i.e. to the mean contact pressure, are increased at the same time as the

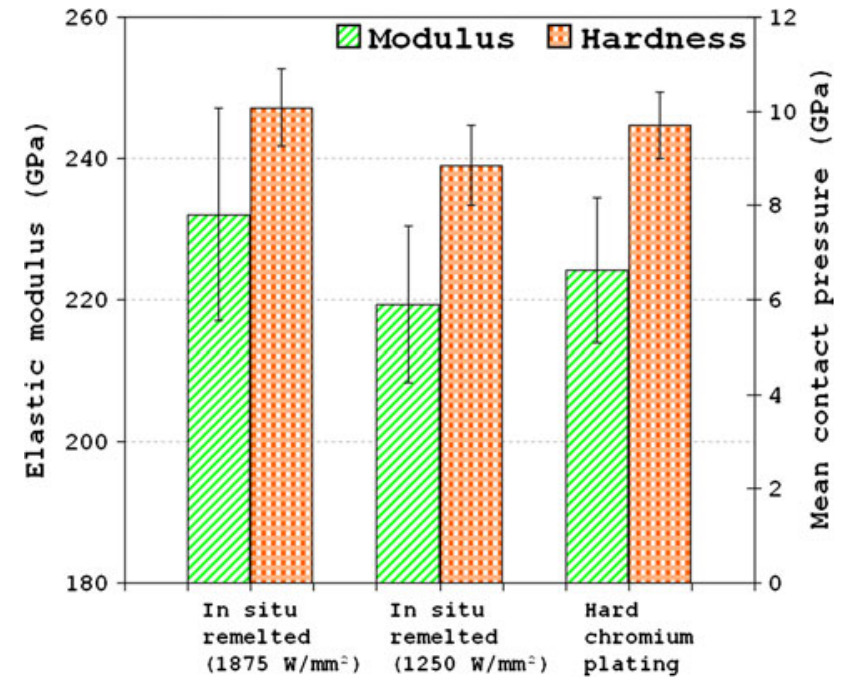

Fig. 10 Mean contact pressure and elastic modulus, which belong to the 1160-00 powder coating, determined using an ultralow load $(30 \mathrm{mN})$ indentation system equipped with a Berkovich indenter tip laser energy density. Furthermore, high chromium content is present in the feedstock material (Table 1) and consequently in the remelted layer. This feedstock material contains B and C; thus it seems that borides and carbides are formed during the in situ laser process, increasing the hardness of the coating. This result is confirmed by XRD analysis (Fig. 9). A limited increase in Young's modulus can be observed for the higher laser power density, even if both remelted samples have similar elastic properties (considering the standard deviation values), which could be due to similar chemical composition.

Based on earlier work (Ref 11), the tribological properties of the laser-treated samples compared with as-sprayed coatings are better. The mechanical properties of the sample remelted at $1875 \mathrm{~W} / \mathrm{mm}^{2}$ are better, and they are closely linked with mechanical properties of the samples carried out via laser cladding (Ref 11). Thus, this processing parameters configuration could build coatings with suitable mechanical properties and make the in situ laser treatment process an alternative to hard chromium plating, for industrial application where wear behavior must be strong. Both hardness and elastic modulus are higher for this sample compared with the electrodeposited sample.

The hard chromium plating shows comparable elastic modulus and hardness values with laser remelted coatings (Fig. 10), although section 3.2 discusses greater scratch damage. This result is exclusively related to the sample microstructures. The crack network of hard chromium coating leads to a microdelamination mode with crack propagation; that is, failure of this sample is due to cohesive damage. On the contrary, the failure mechanism of remelted samples is different. Thus, the normal force needed to produce the detachment of the coating changes even if elastic modulus and hardness values are similar. Moreover, the correlation between this force and the indenter radius is influenced by the plastic deformation behavior of the coated materials, which is strongly dependent on the intrinsic coating properties.

\section{Conclusions}

This paper deals with the properties of NiCrBSi alloy layers obtained using a technology based on the association between an APS plasma gun and a diode laser source. Results show that in situ laser remelting induces the growth of a dendritic microstructure that strongly decreases the as-sprayed coating porosity. In addition, adhesion, hardness, and elastic modulus also increased. No phase transition after laser treatment is observed. A mechanical investigation has demonstrated that the hybrid process presents better mechanical behavior than electrodeposited hard chromium for a specific laser power density. Thus, with specific selected processing parameters, the hybrid studied process appears to be a possible alternative to hard chromium plating, in order to protect mechanical parts. 


\section{Acknowledgments}

The authors gratefully acknowledge the "Région Alsace" for its financial support in the Ecosurf project and the "Véhicule du Futur" Pole, which sponsored this project.

\section{References}

1. G. Bolelli, V. Cannillo, L. Lusvarghi, and S. Riccò, Mechanical and Tribological Properties of Electrolytic Hard Chrome and HVOF-Sprayed Coatings, Surf. Coat. Technol., 2006, 200(9), p 2995-3009

2. D.E. Kimbrough, Y. Cohen, A.M. Winer, L. Creelman, and C. Mabuni, A Critical Assessment of Chromium in the Environment, Crit. Rev. Environ. Sci. Technol., 1999, 29(1), p 1-46

3. Regulation No. 1907/2006 of the European Parliament and of the Council Concerning the Registration, Evaluation, Authorisation and Restriction of Chemicals (REACH)

4. L. Pawlowski, Thick Laser Coatings: A Review, J. Therm. Spray Technol., 1999, 8(2), p 279-295

5. J. Mateos, J.M. Cuetos, R. Vijande, and E. Fernández, Tribological Properties of Plasma Sprayed and Laser Remelted 75/25 $\mathrm{Cr}_{3} \mathrm{C}_{2} / \mathrm{NiCr}$ Coatings, Tribol. Int., 2001, 34(5), p 345-351

6. A. Lanin and I. Fedik, Thermal Stress Resistance of Materials, Springer, 2008

7. S. Sasaki, Tribological Properties of Coating Films Synthesised by Laser Assisted Plasma Spraying, Surf. Eng., 1997, 13(3), p 238-242

8. G. Antou, G. Montavon, F. Hlawka, A. Cornet, and C. Coddet, Microstructures of Partially Stabilized Zirconia Manufactured via Hybrid Plasma Spray Process, Ceram. Int., 2005, 31(4), p 611-619
9. J.M. Miguel, J.M. Guilemany, and S. Vizcaino, Tribological Study of NiCrBSi Coating Obtained by Different Processes, Tribol. Int., 2003, 36(3), p 181-187

10. Alloy Phase Diagrams, Vol 3, ASM Handbook, ASM International, 1992

11. N. Serres, F. Hlawka, S. Costil, C. Langlade, F. Machi, and A. Cornet, Dry Coatings and Ecodesign. Part 2. Tribological Performances, Surf. Coat. Technol., 2009, 204(1-2), p 197-204

12. W. Kurz, C. Bezençon, and M. Gäumann, Columnar to Equiaxed Transition in Solidification Processing, Sci. Technol. Adv. Mater., 2001, 2(1-3), p 185-191

13. A. Conde, F. Zubiri, and J. de Damborenea, Cladding of Ni-CrB-Si Coatings with a High Power Diode Laser, Mater. Sci. Eng. $A, 2002,334(1-2), \mathrm{p} 233-238$

14. E. Lopez, F. Beltzung, and G. Zambelli, Measurement of Cohesion and Adhesion Strengths in Alumina Coatings Produced by Plasma Spraying, J. Mater. Sci. Lett., 1989, 8(3), p 346-348

15. J. Nohava, B. Bonferroni, G. Bolelli, and L. Lusvarghi, New Indentation and Scratch Methods for Characterization of Thermal Sprayed Coatings, Proceedings of the Fourth RIPT, Lille, France, 2009

16. A.C. Fischer-Cripps, Introduction to Contact Mechanics, 2nd ed., Springer, 2007

17. W.C. Oliver and G.M. Pharr, An Improved Technique for Determining Hardness and Elastic Modulus Using Load and Displacement Sensing Indentation Experiments, J. Mater. Res., 1992, 7(6), p 1564-1583

18. J.M. Coulson, J.F. Richardson, J.R. Backhurst, and J.H. Harker, Chemical Engineering, Vol 1, Fluid Flow, Heat Transfer and Mass Transfer, 6th ed., Butterworth-Heinemann, 1999

19. B.S. Yilbas and S.Z. Shuja, Heat Transfer Analysis of Laser Heated Surfaces-Conduction Limited Case, Appl. Surf. Sci., 1997, 108(1), p 167-175

20. N. Serres, F. Hlawka, S. Costil, C. Langlade, F. Machi, and A. Cornet, Combined Plasma Spray and In Situ Laser Melting Treatment of NiCrBSi Powder, J. Opto. Adv. Mater., 2010, 12(3), p 505-510 